\title{
Validation of a Risk-Based Biomarker-Enhanced Scoring System for Lower Respiratory Tract Infections (OPTIMA I Basel)
}

\section{-An Observational Survey}

\author{
Richard X. Sousa Da Silva ${ }^{{ }^{*}}$, Frank Dusemund ${ }^{1 *}$, Christian Nickel $^{2}$, Roland Bingisser ${ }^{2}$, \\ Andreas Huber ${ }^{3}$, Beat Müller ${ }^{1}$, Werner C. Albrich ${ }^{1}$ \\ ${ }^{1}$ Medical University Department of the University of Basel, Kantonsspital Aarau, Switzerland; ${ }^{2}$ Department of Emergency Medicine, \\ University Hospital of Basel, Basel, Switzerland; ${ }^{3}$ Department of Laboratory Medicine, Kantonsspital Aarau, Switzerland. \\ Email: richard-xavier.sousa-da-silva@stud.unibas.ch
}

Received December $13^{\text {th }}, 2012$; revised January $15^{\text {th }}, 2013$; accepted January $22^{\text {nd }}, 2013$

\begin{abstract}
Background: Despiteits recommendation in management guide lines for community-acquired pneumonia (CAP), the CURB65-score is frequently not followed for disposition decisions in clinical routine. We therefore proposed an improved CURB65-A-score, supplemented by proadre nome dull in (ProADM) levels for patients with CAP and other lower respiratory tract infections (LRTIs). In this study, we vali dated this risk-based biomarker-enhanced disposition in patients with LRTIs presenting to the emergency department of the University Hospital of Basel. Methods: In this prospective observational cohort study of 85 patients presenting with LRTIs, site of care was decided by the physicians in charge according to their judgement. Retro spectively the CURB65-A-score was calculated and a virtual disposition assigned. This was compared with the existing disposition in order to identify efficacy of the novel risk-based biomarker-enhanced disposition. Results: The novel disposition criteria considered 14 patients suitable for outpatient treatment compared to 11 in the current disposition $(p=0.5)$. It detected 7 patients to be best treated outside the hospital for nursing reasons, while the current disposition detected only 1 patient requiring geriatric care $(\mathrm{p}=0.09)$. Further, it decreased regular hospitalizations considerably (32 vs. 64, p < 0.001). Conclusion: The novel risk-based biomarker-enhanced disposition is an objective, safe and probably more efficient disposition system to identify outpatient treatment options than the current practice at the University Hospital of Basel.
\end{abstract}

Keywords: Lower Respiratory Tract Infection; Proadrenomedullin; Biomarker-Enhanced Disposition; CURB65-A-Score; Outpatient Treatment

\section{Introduction}

Lower respiratory tract infections (LRTIs), in particular community-acquired pneumonia (CAP), are potentially serious and highly prevalent infectious diseases with a high economic and social burden [1]. CAP is the main cause for death from infectious diseases in the developed world [2]. In the period from 1993 to 2005 the age- and gender-adjusted mortality in CAP decreased from $8.9 \%$ to $4.1 \%(\mathrm{p}<0.001)$, although comorbidities increased. This reduction of in-hospital mortality of inpatients with CAP indicates that pneumonia is a successful example for improved treatment [3]. Still, treatment of CAP creates overwhelming costs. Mostly they are generated in the hospital setting, since the average costs for inpatient

*Equally contributing first authors. treatment of CAP are 8 to 20 times higher than for outpatient treatment [4]. This observation and the fact that Swiss hospitals regularly operate at or beyond maximal bed capacity make improved disposition pathways a research priority, in order to find effective ways for safe outpatient management. The largest contribution to high costs in the treatment of LRTIs is the initial visit on the emergency department that includes diagnostic tests, and the subsequent hospitalization, which by itself accounts for $63 \%$ of overall costs [5]. Concerning the patients it is crucial to realize thata prolonged hospitalization has a direct negative influence on their health status. First, there is a high risk of induction or deterioration of frailty [6]. Second, the length of stay (LOS) is a substantial risk factor for nosocomial complications and infections [6]. Also, previous hospitalization is an independent risk fac- 
tor for suffering from a CAP. Therefore, disposition tools should both prevent unnecessary hospitalizations and reduce LOS [7].

The two most commonly used scoring systems in CAP are the pneumonia severity index (PSI) [8] and the CURB65-score [9]. Low scores suggest the possibility of outpatient treatment based on a very low mortality prediction. Both do not take the host response into account and are limited by moderate sensitivity and specificity for adverse events. One of the limitations of the PSI in particular is its complex 2-stage 20-item design [10]. The CURB65-score has been shown to have a poor sensitivity for adverse outcomes in young and previously healthy patients [11].

To improve the validity of risk-scores, several prognostic biomarkers have been identified that correlate with the severity of LRTIs, such as ProADM, cortisol, urea and Pro-Endothelin-1 (Pro-ET1) [12]. Cortisol for example is as good in predicting severity and outcome of CAP as the PSI [13]. Similar results are obtained by measuring Pro-ET1, which correlates with the severity of CAP and is an independent predictor for ICU admission and mortality [12]. However, neither cortisol nor pro-ET1 provides an additional improvement of clinical scores.

ProADM is a precursor peptide of the endogenous vasoactive hormone adrenomedullin (ADM). ProADM is used for measurement of adrenomedullin levels, since adrenomedullin is hard to measure in blood plasma and the more stable ProADM is secreted equimolarly to ADM [14]. Adrenomedullin is a potent vasodilatator, has a natriuretic effect, and is elevated in congestive heart failure patients [15]. It may even be part of a novel hormonal system controlling circulation [16,17]. The name of this peptide derives from its discoveryin pheochromocytoma tissue emerging from adrenal medulla, where it is also present abundantly. Adrenomedullin has immunomodulatory and bactericidal properties, which may enable it to be a future prognostic biomarker for determining the severity of LRTIs [18]. Therefore, this study shows great interest in ProADM as a diagnostic and prognostic factor.

Based on the finding that ProADMhas shown to increase the prognostic accuracy of clinical scores for mortality and severe adverse events in LRTI [19-21], we identified two optimal ProADM cut-off values ( 0.75 $\mathrm{nmol} / \mathrm{l}$ and $1.5 \mathrm{nmol} / \mathrm{l}$ ) to separate patients into low-risk and high-risk groups. We then combined the CURB65 classes with the ProADM cut-offs to a new risk score termed CURB65-A-score. The new score provided a higher accuracy for adverse events and mortality than the usual CURB65-score [21]. The CURB65-A-score was generated as following: CURB65-A class I was defined as a CURB65-score of 0 to 1 points and a ProADM $\leq 0.75$ nmol/l (Figure 1). It represents the low-risk category and is considered adequate for outpatient treatment. CURB65A class III results whenever the CURB65-score is of 3 or more points, or whenever the ProADM is $\geq 1.5 \mathrm{nmol} / \mathrm{l}$. It represents the high-risk class and requires hospitalization (inpatient treatment) (Figure 1). All other combinations of CURB65-scores and ProADM values result in CURB65A class II (Figure 1), which represents an intermediaterisk, for which short hospitalization for up to 48 hours with subsequent reevaluation is recommended [22].

In a previously realized prospective observational study named OPTIMA IAarau we analyzed the current disposition practice at the Kantonsspital Aaraufor patients with LRTIs, and assessed the potential of CURB65-A-score assisted disposition [22]. It showed that according to the CURB65-A-score there was a large potential of increasing out patient treatment, as in fact more then $90 \%$ of all patients with LRTIs were hospitalized. Further, it identified a great potential to shorten hospitalization, as patients remained hospitalized for a mean of 3.6 days after they had already reached medical stability [22].

In the current study named OPTIMA I Basel we evaluate the potential of the novel biomarker-enhanced CURB65-A-score in the University Hospital of Basel, and compare it with the locally used rather subjective disposition pathway. We also compare the current data with data from the OPTIMA I Aarau study.

\section{Methods}

\subsection{Research Object}

This study is an observational survey to compare the current disposition practice with a novel biomarker-enhanced CURB65-A-score on patients presenting with LRTIs. From September 2010 to December 2011, we enrolled a convenience sample of 85 patients presenting with LRTIs during office hours to the Emergency Department of the University Hospital of Basel. There were no exclusion criteria. Patients were triaged and treated by the physician in charge, who determined the further management without interference by the study team. Site of care was decided according to local guidelines and bed availability.

The local Institutional Review Board (Kantonale Ethik kommissionbeider Basel) classified this study as observational quality surveillance and waived the need for patient informed consent (EKBB 102/10).

\subsection{Disposition of Patients}

The three sites of care summarized as "ASG" disposition pathway, which is currently used in the University Hospital of Basel, are the following (Table 1): Category "A" 


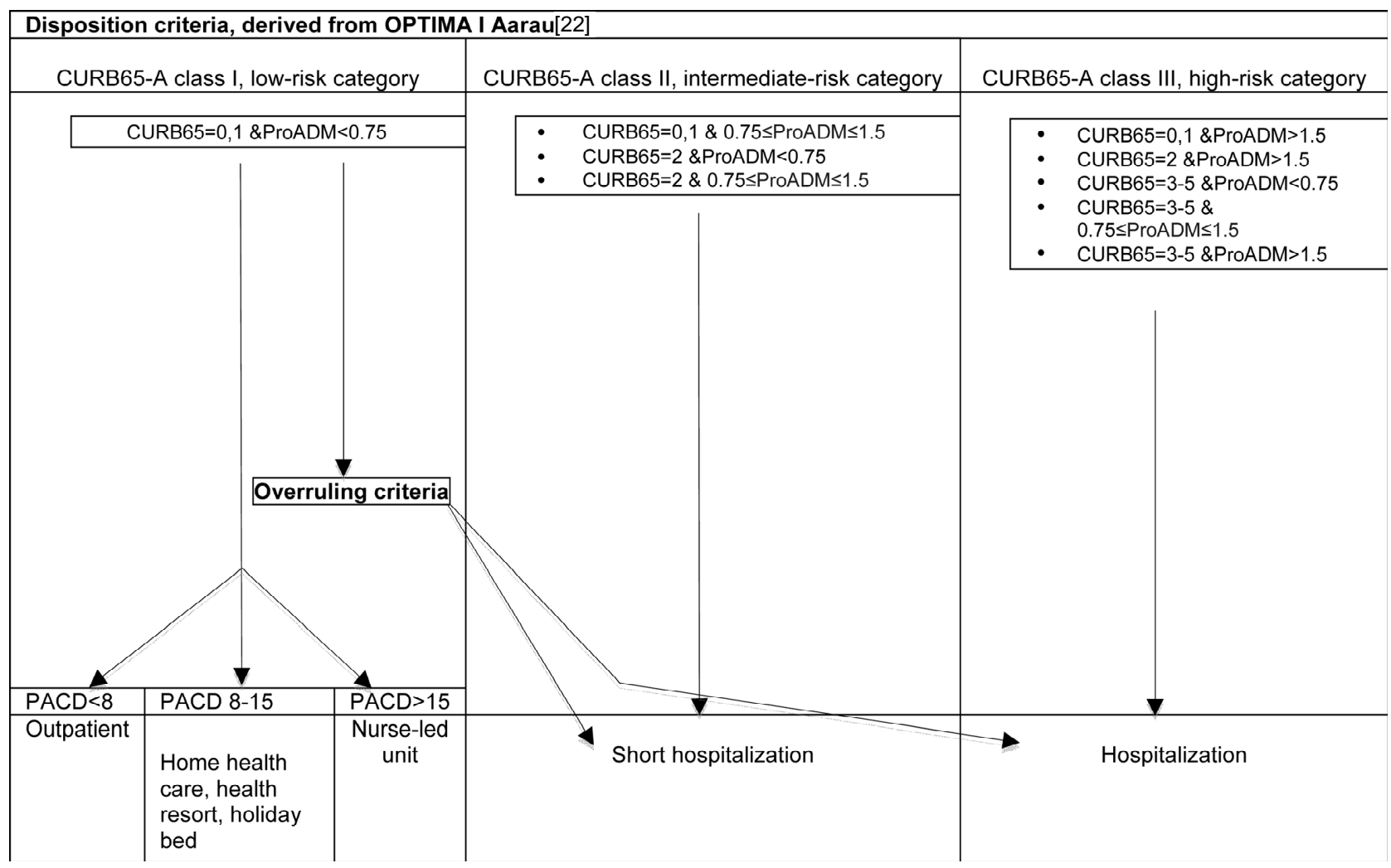

Figure 1. Disposition criteria.

stands for "acute", as when needed hospitalization with further diagnostics and medical surveillance. Category "S" stands for "short", e.g. when there is only the need of a short hospitalization with an overnight stay and discharge to home on the following day. Category " $G$ " stands for "geriatric", e.g. when there is the need of intensive nursing care on a dedicated acute geriatric ward, despite medical stability. All other patients who did not need hospitalization or an overnight stay received out patient treatment, which represents the fourth and last treatment site. The decision of treatment site was taken by the physician in charge according to his judgment, local guidelines and in agreement with the patients and their relatives, but without using any clinical score. The CURB65-A-score [9] was not available for the treating physicians, as it was calculated retrospectively by the research team. The remainder of the phlebotomy specimen of each patient taken on admission day was then sent to the Laboratory Department of Kantonsspital Aarau for measurement of ProADM.

\subsection{Measurement of ProADM}

Measurement of ProADM was performed using a sandwich immunoassay with an analytical detection limit of $0.08 \mathrm{nmol} / 1[22,23]$. The treating physicians had no access to the ProADM values, since these were retrospec- tively measured.

\subsection{Inquiring Adverse Events}

The CURB65-A-score was calculated as described previously (Figure 1) [21]. Each patient received a phone interview on day 30 after presentation to the emergency department, in order to identify adverse events (Table 2). Missing information to calculate the "Selbstpflege index" (SPI = self care index) [24] and the post-acute care discharge score (PACD) [25] was completed at this point as well. Finally, the novel biomarker-enhanced disposition was virtually applied to establish the recommended disposition sites. Low-risk patients (CURB65-A class I) were further categorized regarding the need of nursing supply as determined by the SPI and PACD scores (Figure 1 and Table 3).

\subsection{Endpoints}

Primary endpoints were the comparison of treatment site and adverse events of the actual disposition with the novel risk-based biomarker-enhanced disposition criteria in the University Hospital of Basel. Secondary endpoints were the comparison of adverse events between the low risk subgroups of the CURB65-score and the CURB65A-score. Finally, we compared our findings regarding 
Table 1. Baseline characteristics.

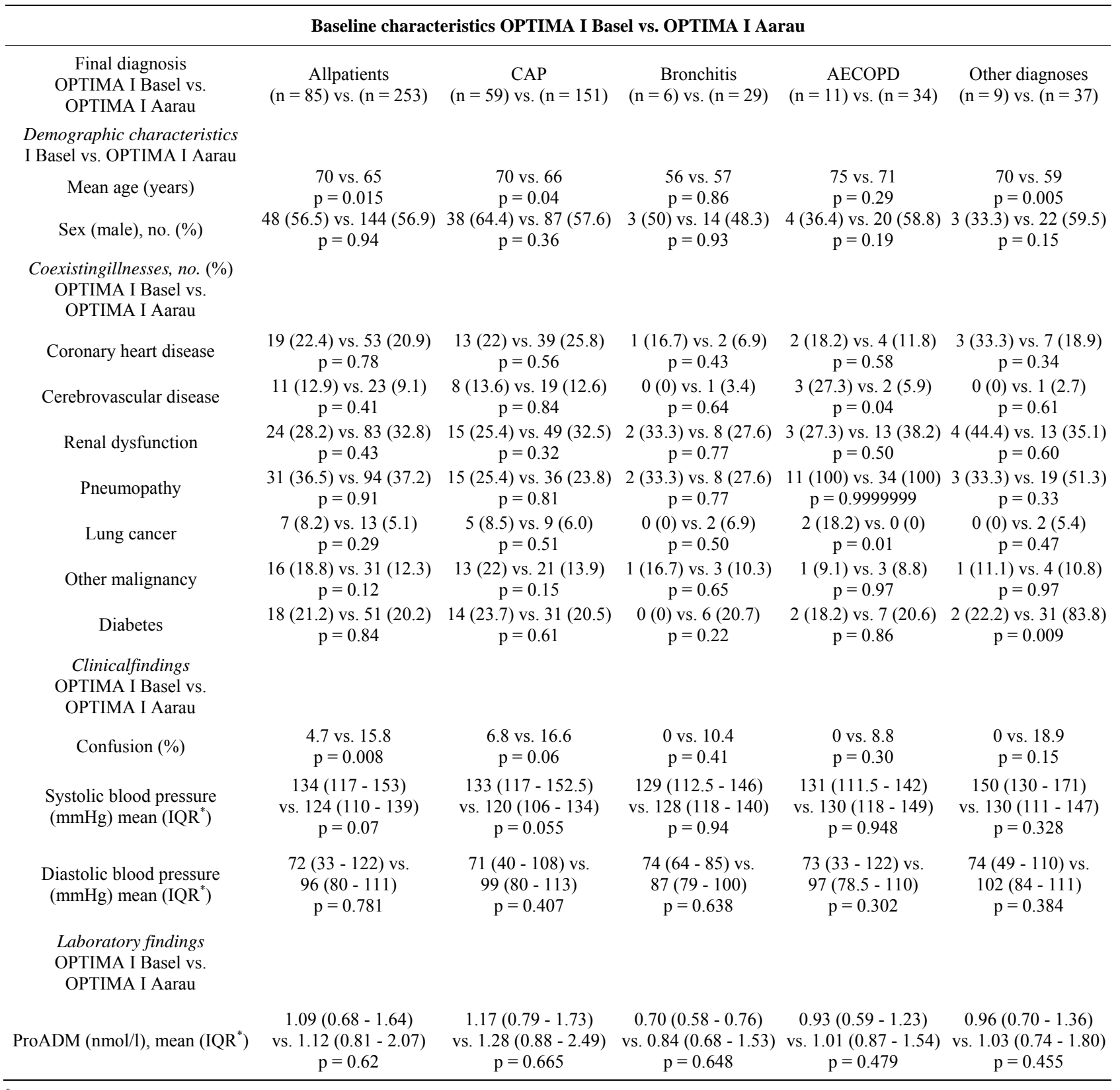

*IQR: Interquartile range.

adverse events and baseline characteristics with those of the precursor OPTIMA I Aarau study [22].

\subsection{Definitions}

LRTI included community-acquired pneumonia (CAP), acute exacerbation of chronic obstructive pulmonary disease (AECOPD), acute bronchitis and a mixed subgroup called "other diagnoses" including for example pleurisy or exacerbation of asthma. Adverse events were assessed on day 30 after admission day based on phone interviews and medical documentation in the hospital. Adverse events included admission to the intensive care unit (ICU), mechanical ventilation, empyema, adverse reaction to antibiotics, death from LRTI and relapse (Tables 2 and 3 ).

\subsection{Overruling Criteria}

By meeting at least one of the following medical overruling criteria, inpatient treatment was considered appropriate, even in the setting of a low CURB65-A-score: 
Table 2. Adverse events in CURB65-score and CURB65-A-score.

\begin{tabular}{|c|c|c|c|c|}
\hline \multicolumn{5}{|c|}{ Adverse events stratified for CURB65-score and CURB65-A-score on patients with LRTIs } \\
\hline $\begin{array}{c}\text { CURB65-score } \\
\text { OPTIMA I Basel vs. } \\
\text { OPTIMA I Aaraup-value }\end{array}$ & $\begin{array}{c}\text { CURB65 0-1 } \\
(\mathrm{n}=37) \text { vs. }(\mathrm{n}=63)\end{array}$ & $\begin{array}{c}\text { CURB65 } 2 \\
(\mathrm{n}=29) \text { vs. }(\mathrm{n}=33)\end{array}$ & $\begin{array}{c}\text { CURB65 3-5 } \\
(\mathrm{n}=19) \text { vs. }(\mathrm{n}=40)\end{array}$ & $\begin{array}{c}\text { Overall } \\
(\mathrm{n}=85) \text { vs. }(\mathrm{n}=136)^{*}\end{array}$ \\
\hline ICU admission & $\begin{array}{c}0(0 \%) \text { vs. } 3(4.8 \%) \\
\text { p }=0.17\end{array}$ & $\begin{array}{c}1(3.4 \%) \text { vs. } 7(21.2 \%) \\
p=0.03\end{array}$ & $\begin{array}{c}2(10.5 \%) \text { vs. } 6(15.0 \%) \\
p=0.63\end{array}$ & $\begin{array}{c}3(3.5 \%) \text { vs. } 16(11.8 \%) \\
p=0.03\end{array}$ \\
\hline Mechanical ventilation & $\begin{array}{c}1(2.7 \%) \text { vs. } 3(4.8 \%) \\
p=0.61\end{array}$ & $\begin{array}{c}0(0 \%) \text { vs. } 5(15.2 \%) \\
p=0.028\end{array}$ & $\begin{array}{c}0(0 \%) \text { vs. } 5(12.5 \%) \\
\mathrm{p}=0.10\end{array}$ & $\begin{array}{c}1(1.8 \%) \text { vs. } 13(9.6 \%) \\
p=0.01\end{array}$ \\
\hline Empyema & $\begin{array}{c}0(0 \%) \text { vs. } 0(0 \%) \\
\text { p }=1.0\end{array}$ & $\begin{array}{c}0(0 \%) \text { vs. } 0(0 \%) \\
p=1.0\end{array}$ & $\begin{array}{c}1(5.3 \%) \text { vs. } 1(2.5 \%) \\
p=0.58\end{array}$ & $\begin{array}{c}1(1.2 \%) \text { vs. } 1(0.7 \%) \\
\text { p }=0.73\end{array}$ \\
\hline Adverse reaction to antibiotics & $\begin{array}{c}0(0 \%) \text { vs. } 1(1.6 \%) \\
\text { p }=0.44\end{array}$ & $\begin{array}{c}1(3.4 \%) \text { vs. } 0(0 \%) \\
\text { p }=0.28\end{array}$ & $\begin{array}{c}0(0 \%) \text { vs. }(0 \%) \\
\mathrm{p}=1.0\end{array}$ & $\begin{array}{c}1(1.2 \%) \text { vs. } 1(0.7 \%) \\
\text { p }=0.73\end{array}$ \\
\hline Death from LRTI & $\begin{array}{c}0(0 \%) \text { vs. } 1(1.6 \%) \\
p=44\end{array}$ & $\begin{array}{c}0(0 \%) \text { vs. } 0(0 \%) \\
\text { p }=1.0\end{array}$ & $\begin{array}{c}0(0 \%) \text { vs. } 4(10.0 \%) \\
p=0.15\end{array}$ & $\begin{array}{c}0(0 \%) \text { vs. } 5(3.7 \%) \\
p=0.07\end{array}$ \\
\hline Relapse & $\begin{array}{c}1(2.7 \%) \text { vs. } 2(3.2 \%) \\
p=0.89\end{array}$ & $\begin{array}{c}0(0 \%) \text { vs. } 0(0 \%) \\
\text { p }=1.0\end{array}$ & $\begin{array}{c}1(5.3 \%) \text { vs. } 5(12.5 \%) \\
\text { p }=0.39\end{array}$ & $\begin{array}{c}2(2.4 \%) \text { vs. } 7(5.1 \%) \\
\text { p }=0.30\end{array}$ \\
\hline $\begin{array}{c}\text { CURB65-A-score } \\
\text { OPTIMA I Basel vs. OPTIMA I } \\
\text { Aaraup-value }\end{array}$ & $\begin{array}{c}\text { CURB65-A I } \\
(\mathrm{n}=21) \text { vs. }(\mathrm{n}=24)\end{array}$ & $\begin{array}{c}\text { CURB65-A II } \\
(\mathrm{n}=32) \text { vs. }(\mathrm{n}=47)\end{array}$ & $\begin{array}{c}\text { CURB65-A III } \\
(\mathrm{n}=32) \text { vs. }(\mathrm{n}=67)\end{array}$ & $\begin{array}{c}\text { Overall } \\
(\mathrm{n}=85) \text { vs. }(\mathrm{n}=138)^{*}\end{array}$ \\
\hline ICU admission & $\begin{array}{c}0(0 \%) \text { vs. } 0(0 \%) \\
\text { p }=1.0\end{array}$ & $\begin{array}{c}0(0 \%) \text { vs. } 4(8.5 \%) \\
\text { p }=0.09\end{array}$ & $\begin{array}{c}3(9.4 \%) \text { vs. } 12(17.7 \%) \\
p=0.26\end{array}$ & $\begin{array}{c}3(3.5 \%) \text { vs. } 16(11.8 \%) \\
p=0.03\end{array}$ \\
\hline Mechanical ventilation & $\begin{array}{c}0(0 \%) \text { vs. } 0(0 \%) \\
\text { p }=1.0\end{array}$ & $\begin{array}{c}1(3.1 \%) \text { vs. } 4(8.5 \%) \\
p=0.33\end{array}$ & $\begin{array}{c}0(0 \%) \text { vs. } 9(13.4 \%) \\
\mathrm{p}=0.02\end{array}$ & $\begin{array}{c}1(1.8 \%) \text { vs. } 13(9.6 \%) \\
\text { p }=0.01\end{array}$ \\
\hline Empyema & $\begin{array}{c}0(0 \%) \text { vs. } 0(0 \%) \\
\text { p }=1.0\end{array}$ & $\begin{array}{c}0(0 \%) \text { vs. } 0(0 \%) \\
\text { p }=1.0\end{array}$ & $\begin{array}{c}1(3.1 \%) \text { vs. } 1(1.5 \%) \\
p=0.58\end{array}$ & $\begin{array}{c}1(1.2 \%) \text { vs. } 1(0.7 \%) \\
p=0.72\end{array}$ \\
\hline Adverse reaction to antibiotics & $\begin{array}{c}0(0 \%) \text { vs. } 0(0 \%) \\
\text { p }=1.0\end{array}$ & $\begin{array}{c}1(3.1 \%) \text { vs. } 1(2.1 \%) \\
\mathrm{p}=0.78\end{array}$ & $\begin{array}{c}0(0 \%) \text { vs. } 0(0 \%) \\
\text { p }=1.0\end{array}$ & $\begin{array}{c}1(1.2 \%) \text { vs. } 1(0.7 \%) \\
\text { p }=0.72\end{array}$ \\
\hline Death from LRTI & $\begin{array}{c}0(0 \%) \text { vs. } 0(0 \%) \\
\mathrm{p}=1.0\end{array}$ & $\begin{array}{c}0(0 \%) \text { vs. } 1(2.1 \%) \\
\mathrm{p}=0.40\end{array}$ & $\begin{array}{c}0(0 \%) \text { vs. } 4(6.0 \%) \\
\text { p }=0.15\end{array}$ & $\begin{array}{c}0(0 \%) \text { vs. } 5(3.7 \%) \\
\mathrm{p}=0.07\end{array}$ \\
\hline Relapse & $\begin{array}{c}0(0 \%) \text { vs. } 1(4.2 \%) \\
\text { p }=0.34\end{array}$ & $\begin{array}{c}0(0.0 \%) \text { vs. } 1(2.1 \%) \\
\mathrm{p}=0.40\end{array}$ & $\begin{array}{c}2(6.3 \%) \text { vs. } 5(7.5 \%) \\
p=0.82\end{array}$ & $\begin{array}{l}2(2.4 \%) \text { vs. } 7(5.1 \%) \\
\text { p }=0.31\end{array}$ \\
\hline
\end{tabular}

"OPTIMA I Aarau; there are two more patients in CURB65-A (138) than in CURB65 (136) because of the patients who had no CURB65-score but a ProADM $>1.5 \mathrm{nmol} / \mathrm{l}$, which classified them directly into CURB65-A III subgroup.

1) Admission to ICU for a) respiratory instability (respiratory rate $\geq 30 / \mathrm{min}$ and $/$ or $\mathrm{O}_{2}$-saturation $<90 \%$ with 61 $\mathrm{O}_{2} / \mathrm{min}$ ) or b) hemodynamic instability (systolic blood pressure $<90 \mathrm{mmHg}$ for $\geq 1$ hour, despite adequate volume resuscitationor vasopressor requirement; 2) Imminent death; 3) Complications (abscess, empyema); 4) COPD GOLD class III or IV with $\mathrm{O}_{2}$-saturation $<90 \%$, despite 30 minutes of intensive treatment; 5) Acute illness requiring hospitalization independent from LRTI; 6) Comorbidity, e.g. immunodeficiency (neutrophils $<500$ / $\mu \mathrm{l}$; if $\mathrm{HIV}+: \mathrm{CD}_{4}<350 / \mu \mathrm{l}$, leukemia, lymphoma, myeloma, cytotoxic medications, hemodialysis), pneumonia within last 6 weeks, antibiotics or hospitalization (independent of indication) within 7 days, other significant lung disease (cancer, fibrosis, bronchiectasis, tuberculosis, pulmonary embolism, cavitarylung disease) and 7) Confusion, delirium or intravenous drug use [22]. Furthermore, by meeting any of the following nursing and organizational overruling criteria the patient was also con ganizational overruling criteria the patient was also considered inappropriate for outpatient treatment: 1) SPIIndex $<32$ points; 2) Criteria requiring intensive nursing care, e.g. dementia, recurrent falls, decubitus ulcer, inability to reliably take medications; 3) Waiting for nonacute medical care, e.g. holiday bed, rehabilitation, nursing home, home health care; 4) Deficit of mobility or self-care requiring treatment; 5) Other reasons, such as inconvenient timing (weekend, night) and 6) Patients' and relatives' preferences: a) concern about safety at home; b) lack of supporting social network; c) other reasons [22].

\subsection{Statistical Analyses}

Discrete variables were reported as counts (percentages), continuous variables as means. Chi-square-test and Mood's-Median-test respectively Mann-Whitney-U-test were applied as appropriate. Test results were considered 
Table 3. Adverse events in ASG disposition pathway and risk-based biomarker-enhanced disposition.

\begin{tabular}{|c|c|c|c|c|c|c|}
\hline \multicolumn{7}{|c|}{ Adverse events stratified for ASG disposition pathway and risk-based biomarker-enhanced disposition on patients with LRTIs } \\
\hline $\begin{array}{l}\text { ASG disposition } \\
\text { pathway }\end{array}$ & $\begin{array}{l}\text { Outpatient } \\
(\mathrm{n}=11)\end{array}$ & $\begin{array}{c}\mathrm{G} \text { (=geriatric) } \\
(\mathrm{n}=1)\end{array}$ & & $\begin{array}{l}\mathrm{S} \text { (= short) } \\
(\mathrm{n}=9)\end{array}$ & $\begin{array}{l}\text { A (= acute }) \\
(\mathrm{n}=64)\end{array}$ & $\begin{array}{l}\text { Overall } \\
(\mathrm{n}=85)\end{array}$ \\
\hline ICU admission & $0(0 \%)$ & $0(0 \%)$ & & $0(0 \%)$ & $3(4.7 \%)$ & $3(3.5 \%)$ \\
\hline Mechanical ventilation & $0(0 \%)$ & $0(0 \%)$ & & $0(0 \%)$ & $1(1.5 \%)$ & $1(1.2 \%)$ \\
\hline Empyema & $0(0 \%)$ & $0(0 \%)$ & & $0(0 \%)$ & $1(1.5 \%)$ & $1(1.2 \%)$ \\
\hline $\begin{array}{l}\text { Adverse reaction } \\
\text { to antibiotics }\end{array}$ & $0(0 \%)$ & $0(0 \%)$ & & $0(0 \%)$ & $1(1.5 \%)$ & $1(1.2 \%)$ \\
\hline Death from LRTI & $0(0 \%)$ & $0(0 \%)$ & & $0(0 \%)$ & $0(0 \%)$ & $0(0 \%)$ \\
\hline Relapse & $0(0 \%)$ & $0(0 \%)$ & & $0(0 \%)$ & $2(3.1 \%)$ & $2(2.4 \%)$ \\
\hline Sum of adverse events & $0(0 \%)$ & $0(0 \%)$ & & $0(0 \%)$ & $8(12.5 \%)$ & $8(9.4 \%)$ \\
\hline $\begin{array}{c}\text { Risk-based } \\
\text { biomarker- } \\
\text { enhanced disposition }\end{array}$ & $\begin{array}{l}\text { Outpatient } \\
(\mathrm{n}=14)\end{array}$ & $\begin{array}{l}\text { Non-acute medical institution }{ }^{*}(\mathrm{n}= \\
\qquad(=\text { CURB65-A class I) } \\
\text { Home health care, health resort, } \\
\text { holiday bed }(\mathrm{n}=7)\end{array}$ & $\begin{array}{l}=21) \\
\begin{array}{l}\text { Nurse-led unit } \\
\quad(\mathrm{n}=0)\end{array}\end{array}$ & $\begin{array}{c}\text { Short hospitalization } \\
(\mathrm{n}=32) \\
(=\text { CURB65-A class II) }\end{array}$ & $\begin{array}{c}\text { Hospitalization } \\
(\mathrm{n}=32) \\
(=\text { CURB65-A class III })\end{array}$ & $\begin{array}{l}\text { Overall } \\
(\mathrm{n}=85)\end{array}$ \\
\hline ICU admission & $0(0 \%)$ & $0(0 \%)$ & - & $0(0 \%)$ & $3(9.4 \%)$ & $3(3.5 \%)$ \\
\hline Mechanical ventilation & $0(0 \%)$ & $0(0 \%)$ & - & $1(3.1 \%)$ & $0(0 \%)$ & $1(1.2 \%)$ \\
\hline Empyema & $0 \quad(0 \%)$ & $0(0 \%)$ & - & $0(0 \%)$ & $1(3.1 \%)$ & $1(1.2 \%)$ \\
\hline $\begin{array}{l}\text { Adverse reaction } \\
\text { to antibiotics }\end{array}$ & $0(0 \%)$ & $0(0 \%)$ & - & $1(3.1 \%)$ & $0(0 \%)$ & $1(1.2 \%)$ \\
\hline Death from LRTI & $0(0 \%)$ & $0(0 \%)$ & - & $0(0 \%)$ & $0(0 \%)$ & $0(0 \%)$ \\
\hline Relapse & $0(0 \%)$ & $0(0 \%)$ & - & $0(0.0 \%)$ & $2(6.3 \%)$ & $2(2.4 \%)$ \\
\hline Sum of adverse events & $0(0 \%)$ & $0(0 \%)$ & & $2(6.3 \%)$ & $6(18.8 \%)$ & $8(9.4 \%)$ \\
\hline
\end{tabular}

"Non-acute medical institution: PACD $<8$ (outpatient), PACD 8 - 15 (home health care, health resort, holiday bed), PACD $>15$ (nurse-led unit).

statistically significant if $\mathrm{p}$-values were $<0.05$. All tests were performed with Microsoft Excel statistical analysis tools and OpenEpi.

\section{Results}

\subsection{Baseline Characteristics}

Of the 85 included patients with LRTIs 59 (69.4\%) had a CAP, $11(12.9 \%)$ an AECOPD and $6(7.1 \%)$ an acute bronchitis. The remaining $9(10.6 \%)$ patients were diagnosed other diseases (e.g. pleurisy). Mean age of all patients was 70 years, and $56.5 \%$ were males (Table 1). The highest mean value of ProADM was observed in the CAP subgroup (1.17 nmol/l), followed by other diagnosis (0.96 nmol/1), AECOPD (0.93 nmol/l) and bronchitis (0.70nmol/1) (Table 1). Comparing the ProADM levels of this study with the precursor OPTIMA I Aarau study shows similar values and similar distribution. In general, baseline characteristics, including distribution of coex- isting illnesses, was similar in both studies, only age andrate of confusionwere significantly higher in the OPTIMA I Aarau study (Table 1). One reason could be the more consequent inclusion of sicker patients, possibly due to the fact that the principle investigators of both observational studies were located in Aarau.

\subsection{Adverse Events}

The comparison of adverse events within each risk category showed no difference between the current study with the precursor OPTIMA I Aarau study (Table 2). Although not statistically significant there is a visible increase in predictability of adverse events in the new CURB65-A-score compared to the CURB65-score when looking at the equivalent low-risk groups, such as CURB65 class 0 - 1 with 2 adverse events (5.4\%) and the CURB65-A class I with no adverse event (0\%) (Table 2).

In the current disposition at the University Hospital of 
Basel none of theoutpatients had any adverse event $(0 \%)$ (Table 3). Neither the single patient of category $G$ (=geriatric) nor the patients of category $\mathrm{S}$ (=short) hadany adverse event (0\%) (Table 3). Among the patients of category A (=acute) 3 patients were admitted to the ICU $(4.7 \%), 1$ required mechanical ventilation $(1.5 \%), 1$ had an empyema $(1.5 \%), 1$ had an adverse reaction to antibiotics (1.5\%) and 2 developed a relapse (3.1\%) (Table 3).

The distribution of adverse events in the new risk categories created by the application of the new riskbased biomarker-enhanced CURB65-A-score would have been as following: none of the patients in the three subgroups of disposition site "non-acute medical institution" had any adverse event ( $0 \%)$ (Table 3$)$. In the intermediate-risk group, where short hospitalization would be recommended, 1 patient would have required mechanical ventilation $(3.1 \%)$ and 1 would have developed an adverse reaction to antibiotics (3.1\%) (Table 3). Finally, in the high-risk group for which hospitalization is recommended there would be 3 cases of ICU admission (9.4\%), 1 case of empyema (3.1\%) and 2 cases of relapse $(6.3 \%)$ (Table 3).

\subsection{Disposition Site}

The current disposition at the University Hospital of Basel (ASG disposition pathway) led to the following distribution: $11(12.9 \%)$ patients were treated as outpatients, $1(1.2 \%)$ patient belonged to category $\mathrm{G}$ (=geriatric) and needed treatment in a geriatric hospital, 9 (10.6\%) patients had a short hospitalization (category S) and 64 (75.3\%) patients were hospitalized (category A) (Table 3). The disposition sites obtained by the new risk-based biomarker-enhanced disposition would have been the following: $21(24.7 \%)$ patients would end up in a nonacute medical institution, while14 (16.5\%) out of them would be treated as outpatients and $7(8.2 \%)$ in either a home health care, a health resort or in a holiday bed (Table 3$)$. 32 (37.6\%) patients would need only a short hospitalization, whereas the other $32(37.6 \%)$ patients would need hospitalization. Further, the new risk-based biomarker-enhanced disposition criteria considered 14 (16.5\%) patients suitable for outpatient treatment compared to 11 $(12.9 \%)$ in the current disposition $(\mathrm{p}=0.5)$ (Table 3). It detected $7(8.2 \%)$ patients to be best treated outside the hospital for nursing reasons, while the current disposition detected only $1(1.2 \%)$ patient requiring geriatric care $(\mathrm{p}$ $=0.09$ ) (Table 3). Most importantly, it shows with only 32 hospitalized patients a significant $(p<0.001)$ decrease in the number of regular hospitalizations compared to the64hospitalizedpatients in the current ASG disposition pathway, represented in category A (=acute) (Table 3).

\subsection{Limitations}

Convenience sample of patients in working hours might have led to selection bias. The low number of enrolled patients is the main limitation of our study. Therefore, it has to be considered a proof-of-concept study for the transfer of a novel triage pathway from one Swiss hospital to another. As a purely observational study, we cannot claim the safety or efficacy, but only the potential for an improved triage, which is being tested in an interventional randomized controlled study at the Medical University Department of the Kantonsspital Aarau at the moment.

\section{Discussion}

This study shows that using the new risk-based biomarker-enhanced disposition would have led to significantly fewer hospitalizations than the current disposition system. Both disposition systems are safe, as no adverse event was identified in the "non-acute medical institution" group (=CURB65-A classI) or in the non-hospital groups of the current disposition system(=outpatients and group G) (Table 3). The new risk-based ProADM-enhanced disposition indicates that several patients could be shifted from the acute hospital setting to nursing facilities resulting in a reduction of costs and nosocomial complications. This suggests that the current more subjective disposition systems may provide less confidence for the treating physicians to select outpatient management, even when the medical risk for the patient is low. This suggestionis consistent with our prior observation that unnecessary fear of potential complications even in low-risk patients is one of the major drivers for hospitalization in Switzerland [26]. This is where we see the opportunity of home health care, health resorts or holiday beds thatwould reduce unnecessary and costly hospitalizations in an acute care facility due to LRTIs. In addition to likely economic benefits, a reduction of unnecessary or unnecessarily long hospitalizations has further benefits, especially considering thatprolonged hospitalization leads to increased frailty [6] and to a higher risk for nosocomial infections [6]. Since the use of ProADM increases the prognostic accuracy of clinical scores for mortality and severe adverse events [19-21], it enables the CUR B65-A-score to be superior to the common CURB65score as previously shown [21] and indicated in this study) (Table 2). An advantage of this novel risk-based biomarker-enhanced disposition compared to clinical scores alone, as for example the pneumonia severity in$\operatorname{dex}(\mathrm{PSI})$, is that it also takes into consideration functional and biopsychosocial factors by using appropriate scores (PACD and SPI) in addition to comorbid illnesses and a set of predefined overruling criteria. This is of 
great importance, given that the most common reason for still hospitalizing low-risk patients is the presence of a comorbid illness [10].

The broad implementation of objective scoring systems like PSI and CURB65-score into daily clinical routine has until now been constricted by either complexity (PSI) or only moderate sensitivity and specificity for adverse reactions (CURB65-score) and by their neglect of comorbid illness, biopsychosocial and organizational factors [10]. These handicaps of previous scores are addressed by the novel risk-based biomarker-enhanced disposition that includesthe new ProADM-enhanced CURB 65-A-score.

\section{Conclusion}

In conclusion, our interdisciplinary biomarker-enhanced risk-based dispositionis an objective tool and might be more efficient in detecting patients for outpatient treatment or treatment in a nursing care facility than the current triage practice at the University Hospital of Basel. Further, his study supports the external validity of Pro ADM-enhanced disposition pathway.

\section{Acknowledgements}

The authors are deeply grateful for the help of the following people that made this survey study possible:

- Ursula Schild for support with data collection;

- Antoinette Conca for support with statistics;

- Josefine Putbrese for patient screening;

- Dr. Natascha Woy, Dr. Anna Messmer and the staff in the Emergency Department of the University Hospital of Basel;

- Renate Hunziker and the staff in the central laboratories of the Kantonsspital Aarau;

- The patients, family members, and caregivers who participated in the study.

\section{Competing Interests}

The OPTIMA project series was supported in part by grants from the Swiss National Science Foundation (32 003B_135222), the scientific council of the KantonsspitalAarau AG and the Ministry of Health of the Canton of Aargau. Werner Albrich and Beat Müller received support from BRAHMS Thermo Fisher and from bioMérieux to attend meetings and fulfill speaking engagements and served as consultants for BRAHMS Thermo Fisher. Beat Müller received research support from BRAHMS Thermo Fisher. All other authors report no conflict of interest. No commercial sponsor had any involvement in design and conduction of this study, namely, the collection, management, analysis, and inter- pretation of the data; and preparation, decision to submit, review, or ap- proval of the manuscript.

\section{Contributors}

WCA and BM had the idea, wrote the protocol and initiated the study, RXSDS and FD managed the trial and collected data, RXSDS and WCA performed the statistical analyses, RXSDS, FD and WCA drafted the manuscript. All other authors amended and commented on the manuscript. All authors approved the final version.

\section{REFERENCES}

[1] T. M. File Jr., "Case Studies of Lower Respiratory Tract Infections: Community-Acquired Pneumonia," The American Journal of Medicine, Vol. 123, No. 4, 2010, pp. S4S15. doi:10.1016/j.amjmed.2010.02.002

[2] D. Mertz and J. Johnstone, "Modern Management of Community-Acquired Pneumonia: Is It Cost-Effective and Are Outcomes Acceptable?" Current Infectious Disease Reports, Vol. 13, No. 3, 2011, pp. 269-277. doi:10.1007/s11908-011-0178-8

[3] G. W. Ruhnke, M. Coca-Perraillon, B. T. Kitch and D. M. Cutler, "Trends in Mortality and Medical Spending in Patients Hospitalized for Community-Acquired Pneumonia: 1993-2005," Medical Care, Vol. 48, No. 12, 2010, pp. 1111-1116. doi:10.1097/MLR.0b013e3181f38006

[4] M. S. Niederman, J. S. McCombs, A. N. Unger, A. Kumar and R. Popovian, "The Cost of Treating CommunityAcquired Pneumonia," Clinical Therapeutics, Vol. 20, No. 4, 1998, pp. 820-837. doi:10.1016/S0149-2918(98)80144-6

[5] S. V. Monte, N. M. Paolini, E. M. Slazak, J. J. Schentag and J. A. Paladino, "Costs of Treating Lower Respiratory Tract Infections," The American Journal of Managed Care, Vol. 14, No. 4, 2008, pp. 190-196.

[6] K. E. Covinsky, E. Pierluissi and C. B. Johnston, "Hospitalization-Associated Disability: 'She Was Probably Able to Ambulate, but I'm Not Sure'," The Journal of the American Medical Association, Vol. 306, No. 16, 2011, pp. 1782-1793. doi:10.1001/jama.2011.1556

[7] Reyes, S. R. Martinez, J. M. Vallés, E. Cases and R. Menendez, "Determinants of Hospital Costs in CommunityAcquired Pneumonia," The European Respiratory Journal: Official Journal of the European Society for Clinical Respiratory Physiology, Vol. 31, No. 5, 2008, pp. 10611067.

[8] M. J. Fine, T. E. Auble, D. M. Yealy, B. H. Hanusa, L. A. Weissfeld, D. E. Singer, C. M. Coley, T. J. Marrie and W. N. Kapoor, "A Prediction Rule to Identify Low-Risk Patients with Community-Acquired Pneumonia," The New England Journal of Medicine, Vol. 336, No. 4, 1997, pp. 243-250. doi:10.1056/NEJM199701233360402

[9] W. S. Lim, M. M. van der Eerden, R. Laing, W. G. Boersma, N. Karalus, G. I. Town, S. A. Lewis and J. T. Macfarlane, "Defining Community Acquired Pneumonia Severity on Presentation to Hospital: An International Derivation and Validation Study," Thorax, Vol. 58, No. 5, 
2003, pp. 377-382. doi:10.1136/thorax.58.5.377

[10] D. Aujesky, J. B. McCausland, J. Whittle, D. S. Obrosky, D. M. Yealy and M. J. Fine, "Reasons Why Emergency Department Providers Do Not Rely on the Pneumonia Severity Index to Determine the Initial Site of Treatment for Patients with Pneumonia," Clinical Infectious Diseases, Vol. 49, No. 10, 2009, pp. e100-e108. doi:10.1086/644741

[11] A. R. Akram, J. D. Chalmers and A. T. Hill, "Predicting Mortality with Severity Assessment Tools in Out-Patients with Community-Acquired Pneumonia," QJM: Monthly Journal of the Association of Physicians, Vol. 104, No. 10, 2011, pp. 871-879.

[12] P. Schuetz, D. Stolz, B. Mueller, N. G. Morgenthaler, J. Struck, C. Mueller, R. Bingisser, M. Tamm and M. ChristCrain, "Endothelin-1 Precursor Peptides Correlate with Severity of Disease and Outcome in Patients with Community Acquired Pneumonia," BMC Infectious Diseases, Vol. 8, 2008, p. 22. doi:10.1186/1471-2334-8-22

[13] M. Christ-Crain, D. Stolz, S. Jutla, O. Couppis, C. Müller, R. Bingisser and P. Schuetz, "Free and Total Cortisol Levels as Predictors of Severity and Outcome in Community-Acquired Pneumonia," American Journal of Respiratory and Critical Care Medicine, Vol. 176, No. 9, 2007, pp. 913-920.

[14] S. Q. Khan, R. J. O'Brien, J. Struck, P. Quinn, N. Morgenthaler, I. Squire, J. Davies, A. Bergmann and L. L. Ng, "Prognostic Value of Midregional Pro-Adrenomedullin in Patients with Acute Myocardial Infarction. The LAMP (Leicester Acute Myocardial Infarction Peptide) Study," Journal of the American College of Cardiology, Vol. 49, No. 14, 2007, pp. 1525-1532.

[15] M. Jougasaki, R. J. Rodeheffer, M. M. Redfield, K. Yamamoto, C. M. Wei, L. J. McKinley and J. C. Burnett Jr., "Cardiac Secretion of Adrenomedullin in Human Heart Failure," The Journal of Clinical Investigation, Vol. 97, No. 10, 1996, pp. 2370-2376. doi:10.1172/JCI118680

[16] K. Kitamura, K. Kangawa, M. Kawamoto, Y. Ichiki, S. Nakamura, H. Matsuo and T. Eto, "Adrenomedullin: A Novel Hypotensive Peptide Isolated from Human Pheochromocytoma," Biochemical and Biophysical Research Communications, Vol. 192, No. 2, 1993, pp. 553-560. doi:10.1006/bbrc.1993.1451

[17] R. Q. Wu, W. F. Dong, X. L. Qiang, Y. X. Ji, T. P. Cui, J. T. Yang and M. Zhou, "Human Vasoactive Hormone Adrenomedullin and Its Binding Protein Rescue Experimental Animals from Shock," Peptides, Vol. 29, No. 7, 200, pp. 1223-1230. doi:10.1016/j.peptides.2008.02.021

[18] D. Bell and B. J. McDermott, "Intermedin (Adrenome- dullin-2): A Novel Counter-Regulatory Peptide in the Cardiovascular and Renal Systems," British Journal of Pharmacology, Vol. 153, No. 1, 2008, pp. S247-S262. doi:10.1038/sj.bjp.0707494

[19] P. Schuetz, M. Wolbers, M. Christ-Crain, R. Thomann, C. Falconnier, I. Widmer and S. Neidert, "Prohormones for Prediction of Adverse Medical Outcome in CommunityAcquired Pneumonia and Lower Respiratory Tract Infections," Critical Care, Vol. 14, No. 3, 2010, p. R106.

[20] M. Christ-Crain, N. G. Morgenthaler, D. Stolz, C. Müller, R. Bingisser, S. Harbarth, M. Tamm, J. Struck, A. Bergmann and B. Müller, "Pro-Adrenomedullin to Predict Severity and Outcome in Community-Acquired Pneumonia," Critical Care, Vol. 10, No. 3, 2006, p. R96.

[21] W. C. Albrich, F. Dusemund, K. Rüegger, M. ChristCrain, W. Zimmerli, T. Bregenzer, S. Irani, et al., "Enhancement of CURB65 Score with Proadrenomedullin (CURB65-A) for Outcome Prediction in Lower Respiratory Tract Infections: Derivation of a Clinical Algorithm," BMC Infectious Diseases, Vol. 11, 2011, p. 112. doi:10.1186/1471-2334-11-112

[22] W. C. Albrich, K. Rüegger, F. Dusemund, R. Bossart, K. Regez, U. Schild and A. Conca, "Optimised Patient Transfer Using an Innovative Multidisciplinary Assessment in Kanton Aargau (OPTIMA IAarau): An Observational Survey in Lower Respiratory Tract Infections," Swiss Medical Wweekly, Vol. 141, 2011, Article ID: w13237.

[23] N. G. Morgenthaler, J. Struck, C. Alonso and A. Bergmann, "Measurement of Midregional Proadrenomedullin in Plasma with an Immunoluminometric Assay," Clinical Chemistry, Vol. 51, No. 10, 2005, pp. 1823-1829. doi:10.1373/clinchem.2005.051110

[24] großeSchlarmann J: Der CMS( $\subset$ imePAC $\odot$. Verschiedene Qualitätsdimensioneneines Instruments. Eineempirische Analyse. Gelsenkirchen: Private Universität Witten/HerdeckegGmbH, 2007.

[25] S. M. Louis, M. P. Kossovsky, P. Chopard, P. Sigaud, T. V. Perneger and J. M. Gaspoz, "A Predictive Score to Identify Hospitalized Patients' Risk of Discharge to a Post-Acute Care Facility," BMC Health Services Research, Vol. 8, 2008, p. 154. doi:10.1186/1472-6963-8-154

[26] C. Baehni, S. Meier, P. Spreiter, U. Schild, K. Regez, R. Bossart, R. Thomann, et al., "Which Patients with Lower Respiratory Tract Infections Need Inpatient Treatment? Perceptions of Physicians, Nurses, Patients and Relatives," BMC Pulmonary Medicine, Vol. 10, 2010, p. 12. doi:10.1186/1471-2466-10-12 